\title{
Posições sexuais, estilos corporais e risco para o HIV entre homens que fazem sexo com homens no Recife (Brasil)
}

\author{
Sexual positions, body styles and HIV risk \\ among men who have sex with men in Recife (Brazil)
}

\author{
Luís Felipe Rios ${ }^{1}$ \\ Amanda Pereira de Albuquerque ${ }^{1}$ \\ Warlley Joaquim de Santana ${ }^{1}$ \\ Amanda França Pereira ${ }^{1}$ \\ Cristiano José de Oliveira Júnior ${ }^{1}$
}

${ }^{1}$ Departamento de Psicologia, Centro de Filosofia e Ciências Humanas,Universidade Federal de Pernambuco. Av. Acadêmico Helio Ramos CFCH/7o, Cidade Universitária. 50670-901 Recife PE Brasil. lfelipe.rios@pq.cnpq.br

\begin{abstract}
The article presents the results of an ethnographic study of the gay community in Recife $(P E)$, conducted via participant observation and interviews. It seeks to understand sexual risk conduct among men who have sex with men (MSM) and HIV, focusing on the significance of sexual positions during anal-receptive intercourse (ARI) and anal-insertive intercourse (AII). Those who practice unprotected ARI are subject to a greater risk of infection than those who practice AII. Those who practice both, ARI and AII, are amplifiers (greater chances of receiving and passing on the virus) in the transmission chains. The text addresses the emic categories related with gender identities - pintosa (female gay), boy (male gay), and cafuçu (MSM and with women, non-gay, male, lower social class) - and with gender identities - active (AII), passive (ARI), and versatile (AII and ARI) - in the ways they result in sexual positions and produce sexual attraction. Masculine men are the most sexually desirable. Boys tend to relate with boys, and pintosas with cafuçus. There is a significant number of versatiles, which increases the collective risk within the gay community. By means of the relations between pintosas and cafuçus, there is increased danger for the virus to circulate more among the gay community and society in general.
\end{abstract}

Key words MSM, Sexual positions, HIV/AIDS, Gender, Homosexuality
Resumo O artigo apresenta resultados de pesquisa etnográfica na comunidade gay do Recife (PE), realizada por meio de observação participante e entrevistas. Objetiva compreender condutas sexuais de risco de homens que fazem sexo com homens (HSH) ao HIV, focando os sentidos das posições sexuais no intercurso anal - receptivo (IAR) e insertivo (IAI). Praticantes de IAR desprotegido são sujeitos a maior risco de infecção que praticantes de IAI. Os que praticam ambos, IAR e IAI, são elos amplificadores (maiores chances de receber $e$ passar o vírus) nas cadeias de transmissão. O texto aborda as categorias êmicas, relacionadas com as identidades de gênero - pintosa (gay feminino), boy (gay masculino) e cafuçu (HSH e com mulheres, não gay, masculino, classe popular) $-e$ com as identidades sexuais - ativo (IAI), passivo (IAR) e versátil (IAI e IAR) —, nos modos como significam as posições sexuais e produzem atração sexual. Os homens masculinos são os sexualmente desejados. Boys tendem a se relacionar com boys, e pintosas, com cafuçus. Há expressivo número de versáteis, o que amplia o risco coletivo dentro da comunidade gay. Por meio das relações entre pintosas e cafuçus, pode existir um caminho propício para o virus circular mais entre a comunidade gay e a sociedade mais ampla.

Palavras-chave HSH, Posições sexuais, HIV/ Aids, Gênero, Homossexualidade 


\section{Introdução}

Este artigo objetiva contribuir para a compreensão das condutas sexuais de risco de homens que fazem sexo com homens (HSH) ao vírus da imunodeficiência humana (HIV), focando os sentidos das posições sexuais no intercurso anal - receptivo (IAR) e insertivo (IAI) - nos modos como são engendrados comunitariamente.

No Brasil, os HSH são uma das categorias mais afetadas pelo HIV/Aids. Esforços têm sido feitos para o enfrentamento da epidemia, como o envolvimento da sociedade civil e do governo em ações comunitárias de prevenção para os HSH e de desestigmatização das homossexualidades na sociedade ${ }^{1}$; distribuição gratuita de preservativos; acesso à testagem para a população em geral e da terapia antirretroviral para as pessoas vivendo com HIV e Aids (PVHA) ${ }^{2,3}$. Não obstante, enquanto a prevalência do HIV estimada para a população em geral ( 13 a 49 anos) é de $0,6 \%(0,8 \%$ para homens) $)^{3}$, estudo realizado em 2008 e 2009 mostra que a prevalência para HSH em 10 cidades variou entre 5,2\% (Recife) e 23,4\% (Brasília), com média de $14,2 \%$ — duas e três vezes maior que a estimada para, respectivamente, mulheres trabalhadoras do sexo e usuários de drogas ${ }^{4}$. Dos 3.449 participantes do estudo, 36,5\% reportaram intercurso anal receptivo desprotegido (IARD) ${ }^{5}$.

Homens praticantes de IARD são sujeitos a maior risco de infecção que os que realizam intercurso anal insertivo desprotegido (IAID) ${ }^{6}$. Uma meta-análise da literatura de língua inglesa apontou que a prevalência entre homens engajados em IAI apenas, IAR apenas e em intercurso anal receptivo e insertivo (IARI) foram de $10,6 \%$, $18,2 \%$ e $19,2 \%$ no período de 1986-2010. Assim, HSH engajados em IAR apenas e IARI foram 1,8 e 2,2 vezes mais prevalentes para o HIV que os engajados apenas em IAI. Fenômeno explicado pelas biologias do ânus e do pênis, sendo o primeiro mais suscetível à infecção que o segundo ${ }^{7}$.

Baseados nesse tipo de informação, muitos HSH têm utilizado o soroposicionamento como estratégia para diminuir o risco (comportamento soroadaptativo $)^{2,8,9}$. No soroposicionamento, a pessoa HIV-negativo só realiza IARD com parceiros de mesma sorologia; caso contrário ou de sorologia desconhecida, opta por IAID $^{8-11}$. Mas o soroposicionamento não elimina o risco de transmissão do HIV e contribui para aumentar a transmissão de outras infecções sexualmente transmissíveis (IST) ${ }^{8,12}$. Em adição, os HSH que praticam intercurso anal receptivo e insertivo desprotegido (IARID) são elos amplificadores (com maiores chances de receber e passar o vírus) nas cadeias de transmissão, aumentando a disseminação do vírus nas comunidades ${ }^{6-8}$.

As posições sexuais também ensejam identidades sociais ${ }^{13,14}$. Uma revisão narrativa de estudos conduzidos na América do Norte, Europa Ocidental e Austrália abordou os significados das posições sexuais entre HSH e risco de infecção pelo HIV. Nesses contextos, praticantes de IAI são denominados tops, de IAR, bottoms, e de IAIR, versatiles. Há categorias híbridas, como bottom versatil e top versatil, sinalizando que, a depender da situação ou do parceiro, amplia-se o espectro de posições. Além de sinalizar posições preferidas, as identidades informam sobre dinâmicas de gênero nos relacionamentos sexuais e afetivos. Tops são representados como mais masculinos, e bottoms, como mais femininos, estereótipos mais enfatizados nas comunidades latinas. Tamanho do pênis também foi associado a identidade sexual. Nessa linha, negros foram representados como predominantemente tops, e asiáticos, como predominantemente bottoms. Os jovens tenderam a se identificar como bottoms, e homens maduros, como tops. Os autores concluem que aspectos pessoais e cognitivos (uso de drogas, saber sobre as hierarquias de risco, por exemplo), categorias sociais (raça/etnia e idade), estereótipos de gênero, com implicações de poder, mediariam posições sexuais e modos de proteção ${ }^{14}$.

No Brasil, em estudos qualitativos é recorrente a problematização sobre identidades sexuais ${ }^{13,15-18}$. No entanto, há poucos trabalhos que as abordam na interface com HIV, em suas implicações epidemiológicas 5 , nos modos como o conhecimento biomédico é apropriado em práticas soroadapitativas ${ }^{10,11}$, ou como as categorias nativas engendram interações ${ }^{13,19,20}$.

Nesses estudos, as posições IAR e IAI são associadas, respectivamente, às identidades sexuais passivo e ativo. Existe um modelo hierárquico de pensá-las e relacioná-las, mais antigo e ainda encontrado nas classes populares, que as alinham às identidades de gênero: o polo feminino/passivo é nomeado bicha, frango, veado ou pintosa, e o masculino/ativo, homem, bofe, boy e cafuçu $u^{15-18}$. A ele se contrapõe outo modelo, associado pelos pesquisadores ao processo de modernização do país, mais presente nas camadas médias, em que haveria uma lógica igualitária: independentemente de posição sexual e de gênero, todos os HSH seriam homossexuais ${ }^{15,17}$.

Os dois modelos foram encontrados vigorando em pesquisas mais recentes dentro das comunidades homossexuais de várias metrópo- 
les ${ }^{13,19-24}$. Muitas vezes, ambos são acionados por uma mesma pessoa para classificar alguém, e a hierarquia se imiscui na igualdade ${ }^{13,19,23}$. As pesquisas apontam para desalinhamentos entre as representações identitárias, performances (sotaque, gestual, vestuário etc.), fontes de prazer corporal (ânus, pênis, boca etc.) e posições sexuais ${ }^{19-24}$. Em adição, as posições se ampliaram do modelo bipolar ativo/passivo, dando passagem para a versatilidade (IARI) ${ }^{13,24}$.

$\mathrm{Na}$ pesquisa objeto deste texto, três categorias de gênero emergiram: boy, cafuçu e pintosa. Em nosso entendimento, elas nomeiam estilos corporais que engendram subjetividades ${ }^{25}$, regulando formas de engajamento na comunidade gay. Cada estilo nomeia o resultado estético e de expressividade que emerge quando o enunciador, na apresentação de sua subjetividade, atualiza elementos corporais, como gestual, sotaque e vestuário, produzindo configurações que têm efeitos de identidade. Ao ocupá-los, os estilos produzem sentidos, emoções e sentimentos, os quais conferem valores e significados às pessoas e direcionam as interações. Pensando na atração sexual como o leitmotiv que integra os HSH em redes sexuais, neste texto exploramos como gênero, raça, classe e fontes de prazer corporal se expressam nos estilos, produzindo atração erótica e apontando direções para onde o HIV caminhar.

\section{Método}

A pesquisa foi realizada entre 2013 e 2015 no município do Recife, capital de Pernambuco, região Nordeste, teve enfoque etnográfico envolvendo observação participante na comunidade homossexual e construção de 25 biografias sexuais por meio de entrevistas. Estas foram realizadas por três graduandos e duas graduandas em psicologia. A amostra foi de conveniência, constituída por meio da rede de relações e delimitada por saturação teórica.

Concebemos as narrativas produtos das entrevistas como janelas para abordar processos de subjetivação ${ }^{26}$. Utilizamos a análise temática ${ }^{27}$ para identificar categorias êmicas utilizadas na significação dos eventos investigados. Neste texto, abordaremos as relacionadas com as identidades de gênero (boy, cafuçu e pintosa) e com as identidades sexuais (ativo, passivo e versátil) nos modos como produzem atração erótica e são utilizadas para dar sentido às posições sexuais dos atores. O Quadro 1 apresenta algumas características dos entrevistados.
Foram entrevistados 10 homens negros, 1 amarelo e 14 brancos (conforme categorias do IBGE), em sua maioria jovens e adultos jovens (entre 18 e 38 anos). Quatorze entrevistados eram estudantes universitários, e destes, dois trabalhavam formalmente. Os outros assumiam postos de trabalho variados, sem grandes exigências quanto à escolarização e com baixa remuneração. Consideramos ocupação/escolaridade como principais indicadores de classe: os de formação universitária foram classificados como de camadas médias, e os outros, como de classe popular. A classificação de gênero foi realizada pelos entrevistadores a partir dos estilos assumidos corporalmente no momento das entrevistas, mediante os sentidos das categorias. Quinze foram classificados como pintosas, e 10, como boys. A identidade sexual, expressão da posição sexual preferida, foi autorreferida: três se disseram passivos, seis, versáteis com preferência pela passividade sexual, 13 , versáteis, dois, versáteis, preferindo ser ativos, e um relatou ser excluxivamente ativo.

Destacamos que, na apresentação dos fragmentos de entrevistas que ilustram as próximas partes deste trabalho, utilizamos colchetes para sinalizar as interferências dos(as) entrevistadores(as) e parêntes para introduzir elementos que ajudem à compreensão das narrativas dos entrevistados. Utilizamos nomes fictícios para guardar o anonimato dos entrevistados. A pesquisa foi aprovada pelo Comitê de Ética em Pesquisa da Universidade Federal de Pernambuco (UFPE).

\section{Resultados}

\section{Recife gay, enfrentamento do HIV/Aids e práticas soroadaptativas}

No Recife, município com cerca de 1,6 milhões habitantes, por ocasião da pesquisa, existiam três boates, quatro ou cinco bares e algumas festas mensais, três saunas e dois ou três cinemas pornôs. Também existiam points gays na praia, em postos de gasolina e no comércio ambulante informal que se estabelece à noite nas cercanias das boates. Nas narrativas, além das salas de bate -papo, sites e aplicativos de buscas de parceiros na internet, também figuram como lugares de busca de sexo banheiros de shoppings e de universidades e parques que ladeiam os rios da cidade.

$\mathrm{Na}$ última década, houve um desinvestimento em campanhas de prevenção do HIV/Aids voltadas aos HSH. Durante a pesquisa, as ações de prevenção na comunidade gay se restringiram a 
Quadro 1. Caracterização dos entrevistados.

\begin{tabular}{|c|c|c|c|c|c|}
\hline Nome & Raça & Idade & Ocupação & Estilo & Posição sexual \\
\hline Bacante & Pardo & 18 & Estudante do ensino médio & Pintosa & Passivo \\
\hline Wagner & Preto & 18 & Cabeleireiro/maquiador & Pintosa & Passivo \\
\hline Eduardo & Branco & 33 & Cabeleireiro & Pintosa & Versátil, mais passivo \\
\hline Hebert & Preto & 24 & Camareiro & Pintosa & Versátil, mais passivo \\
\hline Luan & Branco & 29 & Vendedor & Pintosa & Versátil, mais passivo \\
\hline Marcos & Pardo & 19 & Soldado/estudante universitário & Pintosa & Versátil, mais passivo \\
\hline Caio & Preto & 23 & Soldado & Pintosa & Versátil, mais passivo \\
\hline Gilmar & Pardo & 22 & Estudante universitário & Pintosa & Versátil, mais passivo \\
\hline Leo & Pardo & 18 & Estudante universitário & Pintosa & Versátil \\
\hline André & Pardo & 21 & Estudante universitário & Pintosa & Versátil \\
\hline Fernando & Branco & 22 & Estudante universitário & Pintosa & Versátil \\
\hline Apolo & Branco & 21 & Desempregado & Pintosa & Versátil \\
\hline Márcio & Amarelo & 28 & Estudante universitário & Pintosa & Versátil \\
\hline Antônio & Branco & 38 & Auxiliar de serviços gerais & Pintosa & Versátil, mais ativo \\
\hline Valter & Preto & 22 & Professor de dança & Pintosa & Ativo \\
\hline Eduardo & Branco & 23 & Estudante universitário & Boy & Versátil, mais ativo \\
\hline Alejandro & Preto & 26 & Estudante universitário & Boy & Versátil \\
\hline George & Branco & 34 & Técnico em encanação & Boy & Versátil \\
\hline Manuel & Branco & 21 & Estudante universitário & Boy & Versátil \\
\hline Rodrigo & Branco & 23 & Estudante universitário & Boy & Versátil \\
\hline Tales & Branco & 28 & Estudante universitário & Boy & Versátil \\
\hline Paulo & Branco & 21 & Estudante universitário/entregador & Boy & Versátil \\
\hline Amaral & Branco & 26 & Comerciário/superior concluído & Boy & Versátil \\
\hline Kaik & Branco & 24 & Estudante universitário & Boy & Versátil \\
\hline Daniel & Branco & 18 & Estudante universitário & Boy & Passivo \\
\hline
\end{tabular}

atividades pontuais de distribuição de informativos e insumos nos eventos LGBT de carnaval e na ocasião da Parada da Diversidade Sexual, e na disponibilização de preservativos gratuitos em algumas saunas e cinemas pornôs.

A ausência de intervenção comunitária pode ser um reflexo da perspectiva que tem orientado o Governo Federal nos últimos anos, que, em conformidade com a Unaids, tem focado no tratamento como prevenção, com ênfase em testar e tratar — política embasada em evidências biomédicas de que a pessoa em tratamento e com carga viral indetectável tem menos chances de infectar outras pessoas. Nessa linha, em 2014 e 2015, as campanhas televisivas, lançadas por ocasião do Dia Mundial de Enfrentamento da Aids e do carnaval, enfatizaram a testagem e o tratamento. A eficácia e a efetividade dessa política merecem uma discussão aprofundada, que não cabe neste texto ${ }^{9,28}$. Em todo caso, vale dizer que, embora haja no Recife acesso a testagem gratuita, e, em tese, as PVHA tenham acesso a tratamento e medicação gratuitas, havia grande dificuldade para iniciarem e manterem o tratamento com qualidade ${ }^{29}$.

Todos os interlocutores relataram ter muito medo da epidemia de HIV, e a maioria afirmou utilizar regularmente a camisinha com parceiros ocasionais. No entanto, cenas de exceção foram se multiplicando ao longo das conversas. Ninguém mencionou soroposicionamento como estratégia de reduzir risco; o que predominou foi a soroescolha com base em condições sorológicas presumidas. A confiança em conhecidos, amigos e namorados, de quem se conhecem os hábitos, produziria uma suposição de sorológica negativa. Sub-repticiamente, o corpo belo e saudável (não magro) reitera a presunção. Em situações de muito tesão e ausência de camisinha, esses elementos criam disposição para sexo desprotegido. Os que se expõem ao risco, movidos pelo medo da infecção, esperam findar o período da janela imunológica e buscam o alívio do teste. Com parceiro fixo, a testagem só acontecia após conhecimento ou suspeita de infidelidade ou fim de relacionamento. $\mathrm{O}$ teste surge como tentativa 
de reparação, que não tem eficácia preventiva individual. Embora disponível no Recife, talvez por ser pouco divulgada, ninguém fez menção ao uso de profilaxia pós-exposição (PEP), a reparação eficaz ${ }^{29}$.

\section{Gênero, sexualidade e produção de desejo}

Apresentado o pano de fundo social da resposta ao HIV/Aids e o modo como nossos interlocutores relatam se prevenir, passaremos para o objeto de nossa análise: escolhas de parceiros, posições sexuais e risco.

Os três estilos de ser HSH aqui analisados emergiram nos espaços de homossociabilidade e nas narrativas, mas nenhum de nossos entrevistados se identificou, ou pôde ser identificado, como cafuçu. Cafuçu emergiu no decorrer da análise, quando refletimos sobre a direção dos desejos eróticos de pintosas e de boys. Exploraremos, inicialmente, os dois estilos utilizados para classificar nossos entrevistados; a análise do estilo cafuçu será realizada adiante.

\section{Boys e pintosas}

Tem o gay que é reservado, que é o mais boy. Eles geralmente são mais fortezinhos, tentam forçar a voz. [...] eles querem aparentar ser heterossexuais. [...] A bicha boy, ela se veste assim: ela geralmente bota uma calça apertada, porque geralmente ela malha, é a antiga barbie. [...] Eles usam roupas que geralmente o público hétero gosta. Geralmente, eles não andam com outros homossexuais que são mais pintosos ou assumidos. Eles andam com héteros ou com gays tipo eles. (Valter)

Valter sugere que tanto os boys quanto as pintosas são gays ou bichas. Essa categorização aponta para a assunção identitária como marca dessas identidades. Esse é um ponto importante, porque será um dos elementos da diferenciação entre boys e cafuçus, que não se identificam como homossexuais.

Se o boy tem a passabilidade heterossexual, ao se compor de acordo com caraterísticas de masculinidade, é a feminilidade que marcará o estilo pintosa. Prossegue Valter: Pintosa é aquele que não 'tá de acordo com as normas sociais. Que é um saco isso. Feito eu, mais ou menos. Eu sou meio pintosa também. Mas eu gosto, eu me acho legal. A pinta, como traço (gestos e/ou sotaques não intencionais) de feminilidade, é percebida como algo com que já se nasce:

Desde criança, eu tenho um jeitinho, né? Por exemplo, quando eu era criancinha, eu andava com as mãozinhas muito abertinhas. Aí, minha ama de leite [...] pegava minha mãozinha, fechava assim e dizia "ande assim, meu filho". Ela fazia pressão na minha mão. [...] Então, eu já dava indícios que era afeminado, né? (Márcio).

O esforço dos familiáres para apagá-la está relacionado com o fato de que a pinta é consebida, a partir das normas que regulam gênero e sexualidade na sociedade abrangente, como uma marca que desumaniza os homens ao sinalizar para a identidade homossexual ${ }^{16,21}$. É por causa da discriminação que recai sobre as pintosas que muitos boys evitariam, no dizer de Valter, acompanhá-las em espaco público para não serem percebidos como homossexuais. À semelhança de Márcio, todos os homens femininos passaram por experiências corretivas, e muitos conseguem se camuflar. Afinal, até mesmo para conseguir emprego a pinta interfere:

Já fica mais complicado no termo de alguém soltar gracinha, de você conseguir emprego, em tudo. [...] a maioria dos gays, a gente tem trejeitos femininos, tipo o modo de falar e tal. Alguns não. Aí, já é mais tranquilo, são mais discretos, né? Discretinhos.(Wagner)

Marcos comenta que usa uma maquiagem que criou para esconder o que ele realmente é, tornando-se grosso, rude, características que acredita serem masculinas e que divergem dos trejeitos femininos que espontaneamente o compõem. Não obstante, mesmo sem querer, algumas vezes a pinta escapa, impedindo a discrição.

Já no relato dos boys sobre si mesmos, identificamos que a problematização da homossexualidade como algo que faz sofrer tem menos a ver com identidade de gênero e mais com os significados sobre os desejos e as práticas homossexuais. Não há marcações corporais que permitam a alguém que não domine os códigos da comunidade gay identificá-los como homossexuais.

Eu, por exemplo, eu não demonstro. [...] Por exemplo, minha roupa aqui, você não diz nada! Se você me vê calado aqui, você vai me julgar o quê? Heterossexual. De primeiro ato, assim. Sem me conhecer, de boca fechada. Se eu entrar no ônibus, ninguém vai olhar troncho pra mim! Ninguém vai catucar (sussurrando) "Olha o frango!”. Ninguém vai fazer esse comentário. (Daniel)

As construções corporais, por meio de agências intencionais e não intencionais de gestuais e sotaques, que remetem ao masculino ou feminino, vão se fazendo ao longo da vida, de forma mais ou menos inconsciente. Um processo que se dá sobre a constante vigília e regulação da sociedade. Mas o resultado, em termos de apresenta- 
ção pública, nem sempre é aquele que a família, a sociedade ou o próprio sujeito esperaria ${ }^{30}$. Nesse bojo, é importante destacar que foram muitas as cenas relatadas de violências relacionadas com a feminilidade expressa por homens.

\section{Posições sexuais}

Os entrevistados foram solicitados a falar sobre suas experiências sexuais em seus diferentes aspectos (onde, quando, quem estava presente, posições sexuais e práticas de prevenção). A depender do contexto de interação narrado, as posições assumiram o caráter de prática em uma interação específica ou preferência para obtenção do prazer sexual, assumindo o sentido de identidade sexual. Em relação à última dimensão, três se disseram passivos (apenas IAR), seis, versáteis mais passivos (preferem IAR, mas realizam IAI), 13, versáteis (IARI), dois, versáteis mais ativos (preferem IAI, mas realizam IAR), e um, ativo (realiza apenas IAI).

Como se pode notar, houve predominância da versatilidade sexual, ainda que alguns sujeitos tenham se classificado como exclusivamente passivos ou ativos. Muitos alegaram que, em contextos de parcerias fixas, abriram mão da posição preferida para fazer as vontades do parceiro, como relata Bacante:

[Normalmente nessas tuas relações, tu é mais passivo, mais ativo? Tu tem alguma preferência?] Eu sou passiva (risos). Eu sou passiva, mas meto bala. É não. Eu sou passiva, mas eu já fui sim ativo, mas não é minha preferência, eu não gosto. [De ser ativo?] E eu não sinto a necessidade também de ser ativo. Eu prefiro muito, muito, muito mesmo ser passiva. E eu sempre sou passiva. Agora, claro que tiveram relações que alguns namorados pediram. Eles até diziam que tinham fetiche de saber como seria eu, Bacante, ativo. E, claro, como a gente 'tá numa relação, eu não vejo problema nenhum nisso. E eu já fui, mas não é minha preferência. Eu prefiro ser sempre passivo.

Queremos agregar dados de duas outras fontes, de modo que tenhamos mais evidências para nossa posterior discussão. $\mathrm{O}$ primeiro conjunto de dados foi levantado de um site de busca de parceiros na internet, utilizados por homens afeitos à subcultura dos ursos, residentes no Recife ${ }^{31}$. O levantamento foi realizado em abril de 2014 e, de 349 perfiz cadastrados que preencheram o campo de busca "Postura sexual" [sic], 17,5\% se descreveram como ativos, 18,6\%, como versáteis mais ativos, $32,4 \%$, como versáteis, $12 \%$, como versáteis mais passivos, $12 \%$, como passivos, e $2 \%$, como sem penetração. Resultado parcial (novembro de 2016) de um survey comportamental com 145 HSH da Região Metropolitana do Recife (esperase entrevistar 364 pessoas) aponta que $9 \%$ dos entrevistados relataram ser ativos, 20,7\%, versáteis mais ativos, $40 \%$, versáteis, $20,7 \%$, versáteis mais passivos, $9 \%$, passivos, e $0,7 \%$ não quis responder.

Assim, cerca de metade dos cadastrados no site e 4/5 dos respondentes do survey em andamento relatam IARI. No estudo em discussão, $4 / 5$ dos entrevistados estão abertos à versatilidade. As três pesquisas apontam para a ampla presença IARI na comunidade gay do Recife, e, como mostra a literatura, IARID é um forte fator de risco coletivo para infecção pelo HIV ${ }^{6-8}$.

Por outro lado, nos estudos brasileiros, nos arranjos de gênero a feminilidade da pintosa sugere IAR, e a masculinidade do boy, IAI ${ }^{19,20}$. Dos 10 boys entrevistados, oito relataram ser versáteis, um, versátil mais ativo, e um, passivo. No caso das 15 pintosas, cinco relataram ser versáteis, seis, versáteis mais passivas, uma, versátil mais ativa, uma, ativa, e duas, passivas. Desagregando IAI de IAR, pode-se dizer que 14 das 15 pintosas realizam IAR, e 13 delas, IAI. No caso dos boys, nove dos 10 realizaram IAI, e todos realizaram IAR. Assim, o grosso das práticas sexuais efetivamente realizadas pelas pessoas coloca em questão o modelo idealizado de pensar as parcerias, boy-ativo e pintosa-passivo ${ }^{17,19-24}$.

\section{Hierarquias de sexualidade e de gênero}

Embora a grande maioria (24) de nossos entrevistados pratique IAR, notamos a existência de uma hieraquização das identidades de sexualida$\mathrm{de}^{32}$, em que o passivo é, como disse Daniel, signo de menosprezo.

No universo gay, assim, esse termo de passivo é de menosprezo. Principalmente se você diz que é passivo. Se você chega numa roda de gays e diz "Eu sou passivo", você sofre preconceito dos outros gays. Mesmo você sabendo que, nessa rodinha que você contou isso, tem outros gays passivos, só passivos. Mas eles olham pra você assim e faz "Bicha..." (sic) Tem preconceito, tem! Tem aquele medo de dizer o que eu sou. Eu não sei. Acho que tem aquela visão de que o passivo é aquela figura mais feminina, né? (Daniel)

Para Daniel, na comunidade gay a categoria passivo assume o duplo sentido de gostar de IAR e de ser homem feminino, e é recorrentemente utilizada para se referir de forma negativa a alguém. Nesse sentido, também as identidades de gênero são hierarquizadas. Paulo complementa: 
(Os homossexuais falam:) "Ah! Eu não gosto de afeminado!". Aí, depois tá lá dando o cu (IAR)! Sei lá, tipo... [Aí, dar cu é o...] É, sabe, como se fosse... [...a característica do afeminado?!] É! E também existe um sentido pejorativo pra o cara que dá o cu também, sabe? [Como assim?] "Ah! É passivo!". Tipo, chamar uma bicha de passiva, só passiva, é tipo um xingamento, sabe? [...] A gente brinca falando: "Ai, passiva!", "Não sei quê, passiva!". E é como se fosse um xingamento. Porque tem um sentido pejorativo, né? E, aí, tem falando também a ver com a questão do jeito afeminado de ser. Mas, o que seria dos ativos se não fossem os passivos, né, $e$ afeminados, né? (Paulo)

Xingamento ou brincadeira depreciativa, além de expressões de gosto e de modos de ser, as identidades de sexualidade e de gênero aparecem como marcadores de desigualdades sociais ${ }^{25}$. Reatualizam-se dentro da comunidade homossexual estigmas que desumanizam os HSH na sociedade mais ampla, em que o critério para colocar pinta e/ou dar o cu nos patamares mais baixos das duas hierarquias é o mesmo: são atributos classificados como femininos. Uma forma de operar com as representações de sexualidade e de gênero, que, mesmo não encontrando correlação com as experiências pessoais, reitera a relação de forças de gênero da sociedade mais ampla, em que "o homem/masculino é superior à mulher/feminino". Essa forma de o sistema de gênero operar vai ter repercussões na produção de atrações sexuais.

\section{Gênero e produção do desejo}

A maioria dos entrevistados afirmou que, na escolha dos parceiros sexuais, não se importava com os estilos, boy ou pintosa; não obstante, no processo de entrevista eles foram covocados a descrever os parceiros em cenas sexuais específicas. Constatamos que havia para todos os entrevistados a predominância de parceiros masculinos.

[E como é que, pra tu ficar bem atraído mesmo, como é que tem que ser o jeito deles assim e tal?] Olha, vê só. Primeiro, não dar pinta. Não dê pinta, se der pinta fodeu! Tira a graça do negócio. Se der pinta... Que ande assim com roupas normais, não precisa andar escandaloso e tal, é normal, com roupas normais. Só que eu, por exemplo, eu adoro esse tipo que é roqueiro, mas gosta de fazer jiu-jitsu ou gosta de fazer artes marciais, ou então meio que rapper. (Amaral)

Notamos uma tendência dos homens femininos de classe popular em utilizar o modelo hierárquico ${ }^{19}$ para significar as parcerias. $\mathrm{O}$ casal formado por mulher e homem seria reatualizado nas figuras da bicha e do homem, com as implicações de poder que masculino e feminino engendram nas relações sociais. Wagner relatou não se incomodar com o estilo de um possível parceiro, no entanto diz: mas não pode ser mais gay que eu. Antônio afirmou não gostar de se relacionar com homossexuais (no sentido de pintosa), porque ele já é homossexual, e justifica: Por que eu ia querer ficar com outro igual a mim? Ao ser questionado sobre com quem ele prefere se relacionar, afirmou preferir homens, e explicou que os homens são diferentes dos frangos, pois geralmente $t i$ nham família e filhos. Também diz não gostar de ir a boates, pois lá tá cheio de frango, de homossexual e eu não vou pra lá procurar homem, porque não tem. Só tem como eu.

Os homens femininos de classe média tenderam a utilizar o modelo gay com gay para significar as parcerias, acentuando que, independentemente de estilos e de posições, são dois homens se relacionando ${ }^{15}$. Já os boys entrevistados (na grande maioria estudantes universitários), além de se embasarem no modelo igualitário, afirmam preferir se relacionar com homens também masculinos. Nessa linha, Paulo reitera: Porque, dentro da comunidade gay, os gays não afeminados dizem não curtir gays afeminados, porque eles são afeminados.

Todos os nossos interlocutores afirmaram preferir homens masculinos para se relacionar, sugerindo a existência de um desprestígio erótico e um desinvestimento libidinal coletivo na figura da pintosa. Nesse contexto, a questão que emerge é: com quem as pintosas se relacionam sexualmente?

\section{Rumando para a borda: o cafuçu}

Em um contexto em que o feminino do estilo de ser homem é constantemente objeto de desvalorização erótica, a figura preferida das pintosas é o cafuçu:

Eu gosto de cafuçu, eu gosto de homem mesmo. De sair com homem mesmo. Vou fazer o que numa boate, que eu sei que é tudo veado igual a mim? 'Tá entendendo como é a história? Aí, eu não gosto porque o veado é assim: se tem dois homens morando juntos, todos dois é veado porque um ajuda o outro. Um dá o dinheiro, 'tá entendendo? O outro também dá dinheiro pra pagar o aluguel, pra pagar a luz. Já eu sou diferente. Eu dou àqueles que eu fico, né? Porque eles são homens mesmo. Aí, eu não curto nessa zona não. (Antônio)

Nas representações, o cafuçu é o homem bruto, rude, com movimentos gestuais contidos (em 
oposição à gesticulação dos braços e mãos das pintosas) e ativos na interação sexual. Eles geralmente são ativos, mas ajuda mainha na frente. [...] ele também tem que fazer dinheiro, né? Pra pagar à boyzinha que ele tá namorando. (Márcio).

[Como é o cara cafuçu?] O cara cafuçu é assim: 'que eu rolo com porra de frango'. [Rola com o quê?] 'E eu rolo com porra de frango', quando 'tá bom né, quando 'tá bebo (bêbado) é tudo uma galinha. [Uma galinha é o que? Que pega todos os frangos?] É, pega. Botou dinheiro, minha filha, eles tão dentro. [Ah, então tu sempre paga pra eles?] É, eu dou 50 (reais). Assim, a Rodrigo eu dou 100 (reais) pra ajudar ele. Porque ele tem dois filhos, né? Pra ajudar. (Antônio)

Cafuçu vem de cafuzu, uma classificação para missigenação entre negros e índios. No contexto sinaliza a racialização desse estilo de ser homem: não branco. Em adição, são descritos como homens pobres, que têm relacionamento heterossexual e muitas vezes fazem sexo com bichas por troca (ainda que não formalizada) financeira ou de bens. Eles se percebem homens e se utilizam do modelo hierárquico para significar as interações com as pintosas. Relações quase sempre descritas como ocasionais. Em geral, fazem parte de redes de convivência das pintosas nos bairros de residência ou trabalho.

\section{A lógica dos encontros sexuais}

No caso em estudo, existe um modelo idealizado de pensar os encontros sexuais ${ }^{19,20}$, em que ativos/boys se relacionariam sexualmente com passivos/pintosas. Ainda que o modelo se presentifique em alguns casos, há desalinhamentos entre as posições sexuais e as estilísticas corporais. A maior parte de nossos entrevistados está aberta às possibilidades prazerosas oferecidas pela versatilidade. Os estilos corporais, hierarquizados no sistema de gênero, são mais importantes para produzir e dirigir desejos sexuais que as posições sexuais: as marcas de feminilidade do estilo pintosa produzem um desinvestimento libidinal em seus corpos-subjetividades, e o estilo boy confere o lugar de objeto sexual desejável. Esse arranjo de gênero produz uma tendência à busca de homens masculinos.

Gayle Rubin ${ }^{33}$ sugere que o sistema de sexogênero produz assimetrias (na divisão do trabalho, na produção de interesses sexuais, nos modos de se expressar, nos gostos e nos prazeres) para criar complementaridade e reciprocidade, garantindo, desse modo, a reprodução social e biológica. Ela aponta que as relações afetivo- sexuais, mesmo entre pessoas do mesmo sexo, tenderiam a se pautar pelo modelo masculino/ feminino, reiterando, assim, a operacionalidade do sistema. A busca dos boys por homens masculinos quebra a suposta reciprocidade comunitária que as representações ideais de gênero situam, em que o modelo masculino/feminino deveria se atualizar nas parcerias sexuais.

Nesse contexto de engendramento de seres desejáveis e desejantes, as pintosas tendem a buscar parceiros sexuais entre homens que estão nas bordas da comunidade gay: os cafuçus. Homens masculinos, rudes, ignorantes, pobres, de cor, não gays, que acreditam não ter as próprias identidades sexuais e de gênero ameaçadas ao se relacionar com homens femininos. Por certo, os cafuçus são homens que também estão nas bordas da masculinidade idealizada, homens marginalizados, muitas vezes pouco desejáveis nos olhares das classes médias da sociedade abrangente.

\section{Discussão: estilo, desejo, versatilidade e risco}

Os dados apresentados sobre a resposta ao HIV/ Aids sugerem um contexto de grande vulnerabilidade à infecção pelo $\mathrm{HIV}^{9,19}$, marcado pela carência de campanhas massivas e ações corpo a corpo de distribuição de informações e insumos na comunidade, precariedade na atenção às PVHA, uso irregular do preservativo pelos $\mathrm{HSH}$, utilização de práticas soroadaptativas de baixíssima eficácia e de falta de acesso à $\mathrm{PEP}^{29}$.

Neste texto, exploramos o modo como estilos e posições sexuais podem interferir na vulnerabilidade coletiva ${ }^{14}$. Como mostramos, os estilos corporais são os principais motivadores para a formação das parcerias em um contexto em que a maior parte dos homens está aberta para IARI. O expressivo número de versáteis amplia o risco coletivo dentro da comunidade $g a y^{6,7}$, ainda que a forma como se produz a desejabilidade crie trajetos específicos para o vírus caminhar.

Os boys são os mais desejados, têm mais facilidade de conseguir parceiros dentro da comunidade e preferem se relacionar com boys. Entre eles, há o predomínio da versatilidade (4/5), tornando o risco coletivo alto, mas o modo como se constitui a desejabilidade tenderia a restringir a circulação do vírus entre os próprios boys.

As pintosas são menos desejáveis e têm mais dificuldade de constituir parcerias dentro da comunidade gay. Do ponto de vista de posições sexuais, há predomínio da versatilidade (1/3), mas tendendo à passividade $(2 / 5$ de versátil para 
passivo e 2/15 para passivo). Se a passividade predominar em interações específicas, elas têm mais propensão para se infectar, e têm menor chance de infectar os parceiros, se comparadas aos boys.

As pintosas têm como parceiros privilegiados os cafuçus, que estão nas bordas da comunidade gay, ampliando as redes sexuais rumo a contextos não gays, em especial das classes populares. Convém destacar que, no nível das representações, os cafuçus são descritos como ativos, o que poderia dificultar a propagação do vírus, uma vez que o risco relativo de infecção nas IAID é menor, quando comparado à IARD. De todo modo, por meio da relação entre pintosas e cafuçus, pode existir um caminho propício para o vírus circular mais amplamente entre a comunidade gay e a sociedade mais ampla.

Destacamos a carência de pesquisas sobre a conduta sexual dos cafuçus (bissexuais de classe popular) que permitam verificar se há entre eles a mesma decalagem entre as representações de gênero e posições sexuais existentes entre homens gays identificados. Pesquisa realizada entre homens profissionais do sexo (muitos estilisticamente cafuçus) do Recife aponta para o uso da IAR para hierarquizar os profissionais e valorizar o produto. Os exclusivamente ativos são mais valorizados, mas realizam IAR, negando o prazer na posição e cobrando mais caro por isso ${ }^{24}$.

Não obstante, os cafuçus descritos por nossos informantes não são trabalhadores do sexo e podem operar por outras lógicas. Na linha de compreender melhor as cadeias de circulação do vírus entre diferentes nichos sociais, sublinhamos a necessidade de convergir esforços em estratégias de investigação das condutas sexuais dos homens

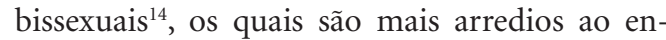
volvimento em pesquisas. Do mesmo modo, há necessidade de aprofundar a compreensão sobre identidades sexuais e identidades de gênero, posições sexuais e desejo na interface com outras dimensões sociais que não puderam ser explorados neste trabalho, como idade, representações sobre o tamanho do pênis, qualidade da ereção com e sem camisinha, conhecimentos e práticas de proteção em relação ao HIV/Aids.

\section{Colaboradores}

LF Rios trabalhou na concepção do projeto, coordenação do trabalho de campo, análise dos dados e redação final; AP Albuquerque, WJ Santana, AF Pereira e CJ Oliveira Júnior trabalharam na coleta e análise dos dados.

\section{Agradecimentos}

Ao $\mathrm{CNPq}$ pelo apoio à pesquisa, aos Programas de Bolsa de Iniciação Científica da UFPE/CNPq e FACEPE. Também agradecemos a Marina Leitão e Clovis Lira pelas contribuições durante a coleta de dados. 


\section{Referências}

1. Brasil. Ministério da Saúde (MS). Coordenação Nacional de DST e Aids. Novos desafios da prevenção da epidemia de HIV/AIDS junto aos homens que fazem sexo com homens (XII Seminário do Programa de Cooperação Técnica Brasil-França). Brasília: MS; 2002

2. Berkman A, Garcia J, Muñoz-Laboy M, Paiva V, Parker R. A critical analysis of the Brazilian response to HIV/ AIDS: lessons learned for controlling and mitigating the epidemic in developing countries. Am J Public Health 2005; 95(7):1162-1172.

3. Brasil. Ministério da Saúde (MS). Programa Nacional de DST, AIDS e Hepatites Virais. Relatório de progresso da resposta brasileira ao HIV/AIDS (2010-2011) - UNGASS. Brasília: MS; 2012.

4. Kerr L, Mota R, Kendall C, Pinho A, Mello M, Guimarães $M$, Dourado I, Brito A, Benzaken A, McFarland W, Rutherford G. HIV among MSM in a large middle-income country. AIDS 2013; 27(3):427-435

5. Rocha G, Kerr L, Brito A, Dourado I, Guimarães, M. Unprotected Receptive Anal Intercourse Among Men Who have Sex with Men in Brazil. AIDS Behav 2013; 17(4):1288-1295

6. Lyons A, Pitts M, Grierson J. Versatility and HIV vulnerability: patterns of insertive and receptive anal sex in a national sample of older Australian gay men. AIDS Behav 2013; 17(4):1370-1377

7. Meng X, Zou H, Fan S, Zheng B, Zhang L, Dai X, Deng M, Zhang X, Lu B. Relative Risk for HIV Infection Among Men Who Have Sex with Men Engaging in Different Roles in Anal Sex: A Systematic Review and Meta-analysis on Global Data. AIDS Behav 2015; 19(05):882-889.

8. The Global Forum on MSM. Serosorting and Strategic Positioning, 2013. [acessado 2014 Nov 9]. Disponível em: http://migre.me/vssRl

9. Ferraz D, Paiva V. Sex, human rights and AIDS: an analysis of new technologies for HIV prevention in the Brazilian context. Rev. Bras. Epidemiol 2015; 18(Supl.1):89-103.

10. Silva L, Iriart J. Práticas e sentidos do barebacking entre homens que vivem com HIV e fazem sexo com homens. Interface (Botucatu) 2010; 14(35):739-752.

11. De Luiz G. O uso da argumentação científica na opção por estilos de vida arriscados no cenário da aids. Interface (Botucatu) 2013; 17(47):789-802.

12. Marcus U, Schmidt A, Hamouda O. HIV serosorting among HIV-positive men who have sex with men is associated with increased self-reported incidence of bacterial STIs. Sexual Health 2011; 8(2):184-193.

13. Rios L. Parcerias e práticas sexuais de jovens homossexuais no Rio de Janeiro. Cad Saude Publica 200319 (Supl. 2):223-232.

14. Dangerfield D, Smith L, Williams J, Unger J, Bluthenthal R. Sexual Positioning Among Men Who Have Sex With Men: A Narrative Review. Arch Sex Behav 2016; 46(4):869-884.

15. Fry P. Para inglês ver: identidade e politica na cultura brasileira. Rio de Janeiro: Zahar; 1983.

16. Parker R. Corpos, prazeres e paixões: a cultura sexual no Brasil contemporâneo. São Paulo: Best Seller; 1991.

17. Parker R. Abaixo do equador - culturas do desejo: Homossexualidade masculina e comunidade gay no Brasil. Rio de Janeiro: Record; 2002.
18. Green A. Além do Carnaval. A homossexualidade masculina no Brasil do século XX. São Paulo: UNESP; 2002

19. Rios L. Homossexualidade, juventude e vulnerabilidade ao HIV/Aids no Candomblé fluminense. Temas em Psicologia 2013; 21(3):1051-1066.

20. Antunes M, Paiva V. Territórios do desejo e vulnerabilidade ao HIV entre homens que fazem sexo com homens: desafios para prevenção. Temas em Psicologia 2013; 21(3):1-19.

21. Rios L. Corpos e prazeres nos circuitos de homossociabilidade masculina do centro do Rio de Janeiro. Cien Saude Colet 2008; 13(2):465-475.

22. Monteiro S, Vargas E, Cecchetto F, Mendonça F. Identidades, trânsitos e diversidade sexual em contextos de sociabilidade juvenil no Rio de Janeiro (Brasil). Cad Pagu 2010; 35:79-109.

23. Simões J, França I, Macedo M. Jeitos de corpo: cor/raça, gênero, sexualidade e sociabilidade juvenil no centro de São Paulo. Cad Pagu 2010; 35:37-78.

24. Souza Neto E, Rios L. Apontamentos para uma economia política do cu entre trabalhadores sexuais. Psicologia e Sociedade 2015; 27(3):579-586.

25. Brah A. Diferença, diversidade, diferenciação. Cadernos Pagu 2006; 26: 329-376.

26. Hammack P, Cohler B. Narrative engagement and stories of sexual identity: an interdisciplinary approach to the study of sexual lives. In: Hammack P, Cohler B, organizadores. The story of sexual identity. Narrative perspectives on the gay and lesbian life course. New York: Oxford University Press; 2009. p. 3-22.

27. Blanchet A, Gotman A. L'enquête et lês methodes: l'entretien. Paris: Armand Colin, 1992.

28. Seffner F, Parker R. Desperdício da experiência e precarização da vida: momento político contemporâneo da resposta brasileira à aids. Interface (Botucatu) 2016; 20(57):293-304

29. Rios L, Albuquerque A, Pereira A, Oliveira Jr C, Santana W, Lira Filho C. Da agonia do tesão ao alívio do teste: práticas soroadaptativas na prevenção do HIV entre homens com práticas homossexuais do Recife. In: Rios L, Vieira L, Queiroz T, organizadores. HIV e AIDS: Desafios rumo a 2030. Recife: EdUFPE; 2016. p. 75-125.

30. Butler J. Cuerpos que importan: sobre los limites materiales y discursivos del "sexo". Buenos Aires: Paidós; 2010.

31. Rios LF. Estética de gênero entre homens com práticas homossexuais frequentadores da comunidade ursina de Recife. In: 28 Reunião Brasileira de Antropologia, 2012, São Paulo. Anais $28^{a}$ RBA. Brasília: ABA, 2012.

32. Rubin $G$. Thinking sex: notes for a radical theory of the politics of sexuality. In: Nardir P, Schneider B, organizadores. Social perspectives in lesbian and gay studies: a reader. London: Routledge; 1998. p. 100-133.

33. Rubin G. O tráfico de mulheres: notas sobre a "economia politica" do sexo. Recife: SOS Corpo; 1993.

Artigo apresentado em 18/12/2016

Aprovado em 16/03/2017

Versão final apresentada em18/03/2017 